Boletín de la Sociedad Botánica de México 48: 145-146, 1988

DOI: $10.17129 /$ botsci.1354

Bol. Soc. Bot. México 48: 145-146 (1988)

\title{
El número cromosómico de Lycium leiospermum I. M. Johnston (Solanaceae)
}

Lycium leiospermum I. M. Johnston (Solanaceae) es una especie del norte de México, aparentemente restringida a una reducida región, pues sólo ha sido recolectada en las cercanías de la confluencia de los estados de Coahuila, San Luis Potosí y Zacatecas (Chiang-Cabrera, 1981), siendo probable su presencia también en Nuevo León.
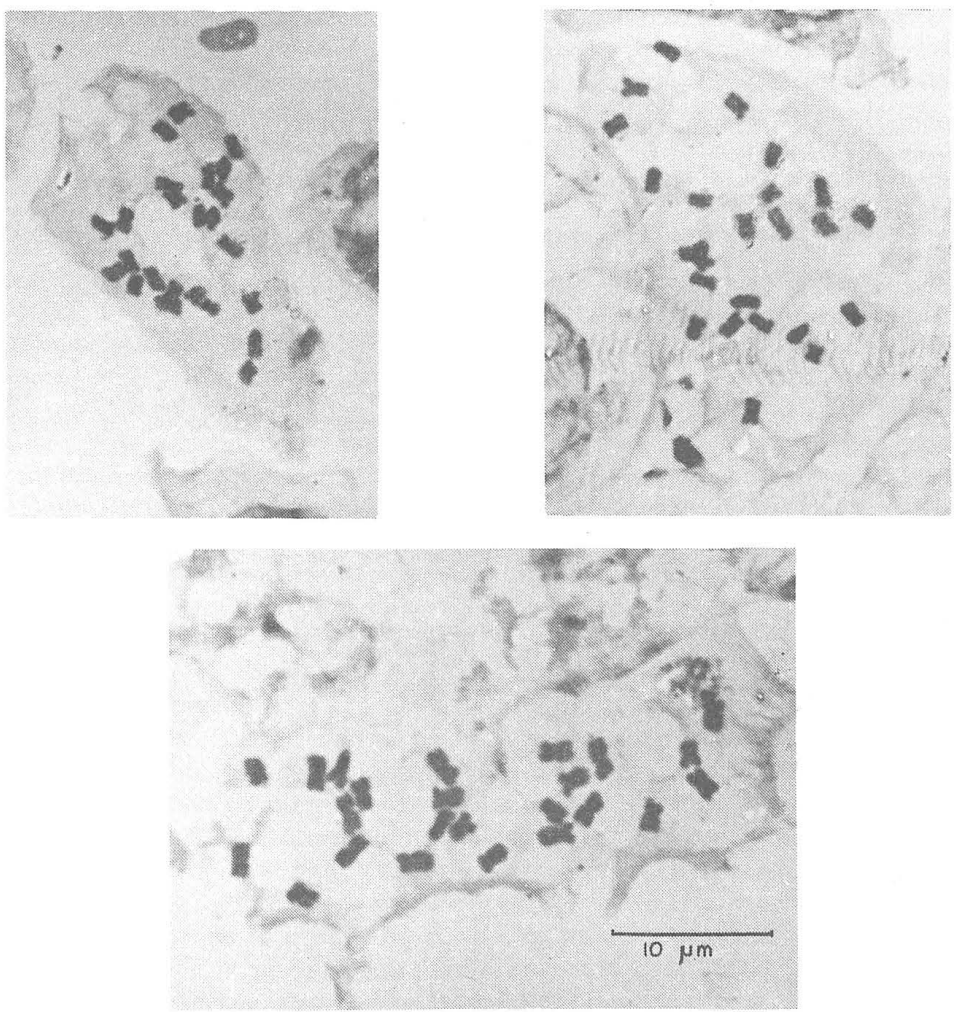

Figura 1. Cromosomas de células meristemáticas de raíz de Lycium leiospermum. Metafase. $2 n=24$.

Chiang F, Viveros R, Mercado P. 1988. El número cromosómico de Lycium leiospermum I. M. Johnston (Solanaceae). Boletín de la Sociedad Botánica de México 48: 145-146. 
El material estudiado (procesado en 1984) proviene del meristemo apical de raíces de plántulas obtenidas en invernadero a partir de semillas del ejemplar Chiang y Almeida 925 (MEXU) (Zacatecas: $7.8 \mathrm{~km}$ al SW del límite de estados Zacatecas-Coahuila, 6.8 $\mathrm{km}$ al SW de la entrada a Puerto de Rocamontes, carretera Zacatecas-Saltillo, (17-VII-1983). Se siguió el método de Feulgen para la tinción de los cromosomas y el de aplastamiento para observarlos.

El resultado de los recuentos es de $2 n=24$ (fig. 1); este número es, de acuerdo con la literatura consultada (Bernardello, 1982; Covas y Hunziker, 1954; Chiang, 1982; Khyos, 1971; Lewis, 1961; Ratera, 1943, 1947; Spellenberg, 1979), el más común para las especies del Nuevo Mundo, así como para las del Viejo Mundo (Chiang, 1982).

Agradecimientos. Se agradece a la Dra. Guadalupe Palomino Hasbach las facilidades brindadas en el Laboratorio de Citogenética (Jardín Botánico, UNAM) a su cargo.

\section{LITERATURA CITADA}

Bernardello, L.M., 1982. Estudios en Lycium (Solanaceae). II. Recuentos cromosómicos en entidades argentinas. Hickenia 1(60):321-328.

Covas, G. y J.H., Hunziker, 1954. Estudios cariológicos en antófitas. IV Parte. Revista Invest. Agr. Buenos Aires 8:249-253.

Chiang, F., 1982. Estudios cromosómicos en Lycium (Solanaceae) de Norteamérica. Bol. Soc. Bot. México 43:9-23.

Chiang-Cabrera, F., 1981. A taxonomic study of the North American species of Lycium (Solanaceae). Ph. D Thesis. University of Texas, Austin.

Khyos, D., 1971. En: I. L. Wiggins y D. M. Porter, Flora of the Galápagos Islands. Stanford University Press, Stanford. p. 468.

LEWIS, W.H., 1961. Chromosomes of North American Lycium (Solanaceae). Texas J. Sci. 13(1):45-48.

Ratera, E.L., 1943. Número de cromosomas de algunas solanáceas argentinas. Revista Fac. Agron. Veterin. 10(2):318-325.

1947. Número de cromosomas de Lycium ciliatum Schlecht. y L. elongatum Miers. Bol. Soc. Argent. Bot. 2(1):43-44.

SpellenberG, R., 1979. Chromosome numbers from some federally proposed threatened or endangered southwestern angiosperms and other miscellaneous taxa. Soutbw. Naturalist 24(1):187-189.

Fernando Chiang, Departamento de Botánica, Instituto de Biología, Universidad Nacional Autónoma de México, Apdo. Postal 70-233, Del. Coyoacán, 04510 México, D.F.

Raúl Viveros y Pedro Mercado, Lab. de Citogenética, Jardín Botánico, Universidad Nacional Autónoma de México, Del. Coyoacán, 04510 México, D.F. 